\title{
Bolívar y Blanco White
}

André Pons

Universidad de París III

Este estudio procura poner de manifiesto la influencia de Blanco White, redactor de El Español (Londres, 1810-1814), en el ideario político de Bolívar, comparando el Manifiesto de Cartagena, la Carta de Jamaica y el Discurso de Angostura con los artículos de Blanco. Después de precisar las relaciones personales del periodista con el Libertador en Londres, se cotejan los textos y se muestra cómo Bolívar se inspiró en el periódico y lo utilizó en un doble sentido: subversivo, con objeto de justificar la lucha anticolonialista, y conservador, para analizar las dificultades de la independencia y de la democracia e imaginar el tipo de gobierno de los nacientes estados.

Los historiadores que se interesan por Bolívar no ignoran que, en su Carta de Jamaica, éste menciona El Español (Londres, 1810-1814), periódico redactado por Blanco White, famoso entre los americanos por haber defendido su causa durante la lucha por la independencia. Ahora bien, al recorrer este texto, o el Manifiesto de Cartagena y el Discurso de Angostu$r a$, el lector de El Español no puede menos que observar coincidencias de ideas o similitudes de forma. Similitudes tan frecuentes que llegan a sugerir irresistiblemente la hipótesis de una filiación directa entre la obra del periodista y los escritos del Libertador. Dicha hipótesis parece reforzada por el hecho, puesto en evidencia en un estudio reciente, de que existe un vínculo estrecho entre la Carta de Jamaica y la Historia de la Revolución de Nueva España o las Cartas al Español de Fray Servando Teresa de Mier. Por eso se plantea el problema de comprobar si no se observa cierta influencia de Blanco White en el pensamiento de Bolívar. Tal es nuestro propósito en este estudio. Seguiremos el método que nos parece más adecuado para ello, o sea que compararemos los escritos más famosos de Bolívar con los artículos de El Español. ${ }^{1}$ Previamente es menester que precisemos las relaciones del periodista con el Libertador.

1 Bolívar, S.: Doctrina del Libertador, Caracas, 1976. Véase Manifiesto de Cartagena, págs. 8-17; Carta de Jamaica, págs. 55-75; Discurso de Angostura, págs. 101-127 (en adelante MC, $C J, D A)$. Blanco White, El Español, Londres, 1810-1814, 8 vol. (en adelante Esp.). Mier, Fray Servando Teresa de: Historia de la Revolución de Nueva España, Londres, 1813. Edición crítica A. Saint-Lu, M. C. Benassy-Berling y otros. París, 1990; véase Introducción, III, Saint-Lu, A.: "Influencia de la Historia en la ideología de la Independencia. Mier y Bolívar", págs. XCIX-CI. Carta de un Americano al Español sobre su número XIX, Londres, W. Lewis, 1811 (Primera Carta, en adelante PC). Segunda Carta de un Americano al Español, Londres, 1812, en González, José Eleuterio: Obras completas, Monterrey, 1888, IX, págs. 143-167 (Segunda Carta, en adelante SC). Pons, A.: Blanco White et la crise du monde hispanique, 1808-1814, Tesis, París, 1990, 4 vols. 
Blanco White trató personalmente a Bolívar en el verano de 1810, cuando éste, encargado por la Junta de Caracas de una misión diplomática en Londres con Andrés Bello y López Méndez, procuró lograr el auxilio de Inglaterra al movimiento del 19 de abril. No hubo una entrevista como se ha creído sino dos. ${ }^{2}$ La primera tuvo lugar en julio de 1810 , cuando el periodista estaba redactando El Español, n. ${ }^{\circ}$ 4, en una fecha que no se puede precisar exactamente pero probablemente entre el 21 , como lo sugiere un corresponsal de Blanco White, y el 30 del mismo mes, día de publicación habitual del periódico. ${ }^{3}$ En sus "Reflexiones políticas" Blanco White saludaba con entusiasmo la revolución de Caracas, recalcaba su moderación y se felicitaba de que no hubiera seguido "los principios exagerados de libertad, las teorías impracticables de igualdad, como los de la Revolución francesa". Los venezolanos se habían levantado para velar por su seguridad contra las autoridades coloniales sospechosas de simpatías francesas; al constituir Juntas, no habían hecho más que seguir el ejemplo de los españoles: habían formado un gobierno interino para ejercer el poder que, en ausencia del rey, había revertido al pueblo. Blanco White aconsejaba a la Regencia que no tomase medidas hostiles, a riesgo de provocar la extensión de la insurrección por todo el continente, y le pedía que aboliese el monopolio, una de las principales quejas de los criollos y una de las causas del levantamiento. ${ }^{4}$

Sin embargo, en otro artículo - "Resumen político"- el periodista cuenta que, teniendo dudas sobre las verdaderas intenciones de los revolucionarios, se atrevió, "por amor a la causa", a consultar a los diputados de Caracas: "los señores Don Luis López Méndez y Don Simón Bolívar". Estos le entregaron una "pequeña nota" que justificaba el movimiento por la exigencia de seguridad e insistía en que "los sentimientos de fidelidad al soberano y de adhesión a la metrópoli habían sido renovados como en 1808 ". Nota que Blanco White reprodujo a la letra y le permitió "anunciar que la revolución de Caracas [no era] en nada hostil a la metrópoli” sino que era un movimiento moderado y antifrancés. ${ }^{5} \mathrm{Si}$ se sitúa este episodio en la campaña de propaganda que lanzaron los diputados de Caracas en la

2 Fuentes, Juan Francisco: "Bolívar y la independencia en las publicaciones periódicas de los exiliados españoles en Londres: el caso de José María Blanco White”, en Alberto Filippi, ed.: Bolívar y Europa, Caracas, 1986, vol.1, págs. 165-183.

3 Sydney Jones Library, Liverpool. J. Allen a Blanco White, 21 de julio de 1810. Mendoza, Cristobal: Las primeras misiones diplomáticas de Venezuela, Madrid, 1962, T. I, págs. 262 y ss. y 274.

4 "Reflexiones políticas", Esp. n. ${ }^{\text {4, } 30}$ de julio de 1810, T. I, págs. 315 y ss.

5 "Resumen político", ibídem, págs. 320 y ss. 
prensa londinense ${ }^{6}$ es lícito pensar que Bolívar aprovechó la oportunidad que le ofrecía Blanco White al pedirle un complemento de informaciones, para propagar a través de El Español, amigo de la causa, la idea de que la revolución no era separatista sino antibonapartista. Tesis que no dejó de mantener en sus negociaciones con Lord Wellesley, pues correspondía a uno de los objetos esenciales de su misión.

La segunda entrevista de Blanco White con Bolívar sucedió en septiembre de 1810, después de terminar las negociaciones con el gobierno británico (9 de septiembre de 1810) y un poco antes de la salida de Bolívar para Portsmouth (16 de septiembre de 1810) donde se embarca en el "Shappire" el 22 para Caracas. Por una carta del 19 de ese mismo mes de Blanco White a J. Allen, sabemos que "unos días antes", por el intermediario de Ricardo Wellesley, hijo del marqués, amigo suyo y amigo de Miranda, el periodista fue invitado a una cena dada por Miranda con motivo de la despedida de Bolívar. ${ }^{7}$ Fue sin duda aquel día — quizás el 13 de septiembre de 1810 - cuando Blanco White confió a Bolívar una carta para Roscio, secretario de Relaciones Exteriores del Gobierno de Caracas, con la misma fecha, en la que el periodista, dirigiéndose especialmente a los americanos, ofrecía sus servicios a la Junta y proclamaba su amor a la libertad de América y a la justicia. ${ }^{8}$ Lo cierto es que Bolívar fue el portador de la carta y la entregó a su destinatario el mismo día en que llegó a Caracas y rindió cuenta de su misión a Londres (7 de diciembre de 1810). ${ }^{9}$ En su equipaje llevaba también para Roscio varios ejemplares de El Espanol. ${ }^{10}$ Este contestó inmediatamente, encargando a López Méndez que diera las gracias al periodista. ${ }^{11}$ Más tarde Roscio iba a darle prueba de su agradecimiento, nombrándole ciudadano de honor de Caracas por haber sido el primero que había defendido su causa. ${ }^{12} \mathrm{Si}$ añadimos que se menciona varias veces El Español en la correspondencia de los enviados por

6 López Méndez a la Junta de Caracas, 2 de octubre de 1810, en Mendoza: Las primeras misiones..., págs. 332 y ss.

7 British Library, Add. Mss. 52194, f. 8. Blanco White a J. Allen, 19 de septiembre de 1810.

8 Blanco White a Roscio, 13 de septiembre de 1810, "El Español a los Americanos" en Gaceta de Caracas (en adelante GC), 1810-1812, Madrid, 1960.

9 "Por el mismo conducto ha recibido S.A. el adjunto oficio del Redactor del periódico El Español...”. El mismo conducto no es otro que Bolívar mencionado en la línea anterior. GC, 11 de diciembre de 1810, pág. 4.

10 López Méndez a la Junta de Caracas, 2 de octubre de 1810, en Mendoza: Las primeras misiones..., págs. 332 y ss.

11 Roscio a López Méndez, 7 de diciembre de 1810, ibídem, pág. 350.

12 Roscio a Blanco White, 28 de enero de 1811, Esp. n. ${ }^{\circ}$ 16, 30 de julio de 1811, III, pág. 295. 
la Junta, basta lo dicho para mostrar las relaciones de confianza y ayuda mutua que se establecieron inmediatamente entre Blanco White y Bolívar o el gobierno de Caracas, relaciones que con éste duraron hasta la caída de la Primera República.

Más precisamente, en aquellos meses de verano de 1810, cruciales para Venezuela, Bolívar, que tenía como objetivos esenciales evitar la guerra con España y conseguir la ayuda o por lo menos la neutralidad benévola de Inglaterra, no podía menos que reconocer el apoyo que El Español prestaba a su propia acción. Efectivamente, al insistir sobre la "moderación" de los americanos, al defender con talento sus derechos y una política de conciliación, Blanco White prestó un señalado servicio a la causa, contribuyendo a disponer la opinión en favor de los insurgentes. El efecto de esta propaganda, difundida también por el Morning Chronicle y The Times, fue incalculable. El mismo Bolívar contribuyó personalmente a ella y se inspiró en El Español en su primer escrito en Londres. En una fingida carta con fecha de Cádiz, 8 de agosto de 1810, firmada por "un caballero español", publicada por el Morning Chronicle (5 de septiembre de 1810), hace hincapié en la moderación de Caracas y en la ausencia de resentimiento de los americanos por los agravios pasados, moderación que opone a los decretos hostiles de la Regencia, que pueden ocasionar la separación de Venezuela y de la América del Sur. Lo curioso del caso es que estas ideas ya se encontraban en El Español y que el párrafo sobre la moderación presenta similitudes literales con un pasaje del "Resumen político" que Bolívar al parecer no hace más que condensar, como lo muestra el cotejo de ambos textos. ${ }^{13}$

Más tarde, El Español, siguiendo su línea inicial, defendió los derechos de los americanos, especialmente la autonomía, censuró duramente la política torpe y hostil de los gobiernos peninsulares y denunció la ilusión de toda solución militar. Anunció el futuro de la libertad en América y afirmó rotundamente que la independencia respondía a una necesidad

13 "As soon as we received the first intelligence from Venezuela, we directed our attention to that country, and we observed with pleasure a spirit of moderation in their proceedings which prejudiced us in their favour, especially when we saw that on breaking the chains that oppressed them, they did not indulge their resentment or abuse the liberty they had acquired..." Morning Chronicle, 5 de septiembre de 1810, pág. 2, col. 3. "Desde el momento en que apareció en los papeles públicos la noticia de la declaración de Venezuela, todos los hombres amantes del bien general y no fascinados por los intereses mal entendidos de patria se pagaron del tono de moderación que respiran las expresiones y medidas del nuevo gobierno de Caracas... se temía si la voz independencia significaría abandono, y si algún resentimiento influiría en los ánimos de los americanos cierta aversión a sus paisanos de Europa..." "Resumen político", Esp. n. ${ }^{\text {4 }}$, 30 de julio de 1810, T. I, pág. 323. 
histórica. ${ }^{14}$ Sin embargo, criticó la declaración de independencia de Venezuela (1811) por parecerle prematura, lo que provocó una polémica con Mier, "el Americano", que defendía la separación inmediata y absoluta. Huelga decir que esta doctrina — con excepción de la tesis de la independencia prematura - reflejaba los deseos de los criollos y respondía a sus intereses; Roscio, conocido como el "teólogo de la independencia", no sólo difundió copiosamente los escritos de Blanco White en la Gaceta de Caracas sino que se valió de su doctrina para justificar la independencia. No hay que extrañarse, pues, de que Bolívar, después de su estancia en Londres, haya seguido leyendo y utilizando El Español, cuyo idealismo militante coincidía con sus propias aspiraciones y servía, con una eficacia que él mismo había comprobado, a la causa de sus compatriotas.

El primer escrito político importante en que Bolívar parece acordarse de El Español, aunque sólo lo menciona en la Carta de Jamaica, es el Manifiesto de Cartagena (15 de diciembre de 1812). En él se observan muchas coincidencias de ideas o de vocabulario con artículos anteriores de Blanco White, especialmente la "Carta al Americano sobre la rendición de Caracas" (El Español, n. ${ }^{\circ}$ 30, 30 de octubre de 1812). Como los plazos de transmisión del correo no se oponían a que Bolívar tuviera conocimiento de este número, se puede plantear la hipótesis de la influencia de éste sobre Bolívar. ${ }^{15}$

En este primer gran documento político de la revolución, Bolívar analiza los fallos de la Primera República y trata de sacar las lecciones de su fracaso. Buscando las causas de éste, señala cinco. Ahora bien, si nos referimos a la "Carta al Americano", observamos que Blanco White - con propósito idéntico- había enunciado por lo menos tres de estas causas: constitución democrática y federal inadaptada al pueblo, terremoto explotado por el fanatismo clerical, divisiones internas. Añadamos que el periodista había señalado la falta de medios financieros y militares para defender la provincia, observación que puede asimilarse fácilmente a la carencia de un ejército permanente y al despilfarro financiero que lamenta Bolívar.

Lo más curioso es otra coincidencia en un punto capital: la jerarquía de las causas. Blanco White y Bolívar consideran que el terremoto era una causa inmediata y accidental del colapso de la República, pero que la cau-

14 Blanco White a Roscio, Londres, 11 de julio de 1811, Esp. n. ${ }^{\circ} 16,30$ de julio de 1811, T. III, pág. 303.

$15 M C$, págs. 8-17. Aunque los plazos de transmisión del correo eran muy variables, un mes bastaba para que las noticias de Londres llegasen a Caracas. Pons: Blanco White..., 3. ${ }^{a}$ parte, cap. III, n. 45. 
sa fundamental era el sistema democrático y federal. La catástrofe no hubiera podido tener consecuencias tan funestas si no la hubiera precedido un error político de los gobernantes: un Congreso federal, débil, consecuencia de los principios democráticos a la francesa y especialmente la igualdad. ${ }^{16}$ Lo recalca Bolívar: "Pero lo que debilitó más el Gobierno de Venezuela fue la forma federal que adoptó, siguiendo las máximas exageradas de los derechos del hombre...". Más adelante reconoce que este sistema todavía no convenía a los estados americanos nacientes y concluye que había que elegir un gobierno adaptado a los pueblos.

Ahora bien, si nos referimos a la crítica que Blanco White había hecho contra la independencia absoluta de Venezuela desde un punto de vista antidemocrático y antifederal, comprobamos que estos pasajes presentan muchas analogías con las ideas de El Español: que la Declaración francesa de 1789 - "principios exagerados" de libertad e igualdad - no podía aplicarse a un pueblo ignorante y supersticioso porque llevaba a la anarquía y luego a la esclavitud; que los americanos aún eran incapaces de ejercer la democracia porque no habían sido preparados para ella bajo el despotismo español; que el federalismo estaba inadaptado a América porque provocaba la división y la debilidad cuando necesitaba unidad y fuerza; que los jefes revolucionarios debían tener en cuenta el carácter y las circunstancias de los pueblos. Éstas eran las tesis que había sostenido Blanco White, especialmente en su polémica con Mier. ${ }^{17}$ La coincidencia general del análisis y del enfoque - conservador y pragmático- induce a pensar que Bolívar, después de leer El Español, adoptó ciertos elementos importantes de su crítica, tanto más que ésta había sido confirmada por los acontecimientos. Esta impresión viene reforzada por similitudes casi literales, que, aunque dispersas, nos parecen significativas por su frecuencia. Primer ejemplo: después de insistir en la debilidad del sistema federal y sus efectos lamentables, Bolívar observa la necesidad de elegir un gobierno adaptado al pueblo:

"Es preciso que el gobierno se identifique, por decirlo así, al carácter de las circunstancias de los tiempos y de los hombres que lo rodean".

16 "Carta al Americano sobre la rendición de Caracas", Esp. n. ${ }^{\circ}$ 30, 30 de octubre de 1812, T. V, págs. 410-426, especialmente pág. 415.

17 "Independencia de Venezuela", Esp. n. ${ }^{\circ}$ 19, 30 de octubre de 1811, T. III, págs. 42-50, "Resumen", ibídem, págs. 79-80; "Contestación... a la Carta de un Americano al Español, sobre su n. ${ }^{\circ} 19 "$, Esp. n. ${ }^{\circ} 24,30$ de abril de 1812, T. IV, págs. 409-425; "Contestación a la Segunda Carta de un Americano al Español", Esp. n. ${ }^{\circ} 28,30$ de agosto de 1812, T. V, págs. 274-285; "Carta al Americano", Esp. n. ${ }^{\circ}$ 30, T. V, págs. $410-426$. 
Huelga decir que enuncia aquí un principio de relativismo político, sostenido por ejemplo por Montesquieu, cuya influencia en el pensamiento del Libertador está comprobada. ${ }^{18}$ Pero no es punto indiferente advertir que en su "Carta al Americano", Blanco White, nutrido de Montesquieu y de Burke, había dado el mismo consejo a los jefes revolucionarios:

“...que calculen el carácter y las circunstancias de los pueblos a quienes excitan a ganar su libertad...." ${ }^{19}$

Otro ejemplo: la crítica de los jefes republicanos. Con un enfoque pragmático y conservador que revela al hombre de acción preocupado por la eficacia y el orden, Bolívar, en un párrafo muy cáustico, denuncia las utopías de los revolucionarios, "filósofos" que no tenían otra "ciencia del gobierno" que la que habían sacado de "los códigos" y cuyos principios habían llevado a "una disolución universal". Merece atención este pasaje, pues recuerda muy exactamente las críticas de Blanco White contra los jefes republicanos. Siempre en la "Carta al Americano", con un enfoque idéntico y con el mismo tono irónico, se había burlado de su inexperiencia política, de su idealismo utópico y de sus pretensiones a dirigir el país sin conocer otra cosa que indigestos principios sacados de "los tratados de derecho natural y de política". Esa ciencia libresca y la aplicación de los principios revolucionarios franceses a un pueblo que no estaba preparado para entenderlos, llevaban inevitablemente a la destrucción del "orden social establecido" y a la "desorganización universal". ${ }^{20}$

Si cotejamos los dos textos, comprobamos ciertas similitudes. Parece que Bolívar, sin duda de manera inconsciente, se acuerda de ciertas expresiones de Blanco White, dándoles una forma más concisa. El término "filósofos", aplicado a los gobernantes para burlarse de su idealismo, se halla en los dos textos; los "tratados de derecho natural y de política" se transforman en "códigos" en Bolívar; la expresión "orden social establecido" se abrevia en "orden social"; la "desorganización universal" se modifica en "disolución universal". En cuanto a la ignorancia de "la ciencia práctica del gobierno" que lamenta Bolívar, se encuentra a la letra en un número anterior de El Español y en forma menos concisa en la "Carta al

$18 M C$, pág. 12. Belaunde, V.A.: Bolívar y el pensamiento político de la revolución hispanoamericana, Madrid, 1959; Brading, D. A.: Prophecy and Myth in Mexican History, Cambridge, 1964, págs. 37-53.

19 “Carta al Americano", Esp. n. 30, T. V, págs. 422-423.

20 MC, pág. 9; "Carta al Americano", Esp. n. ${ }^{\circ} 30$, T. V, págs. 418-424. 
Americano". ${ }^{21}$ Para explicar esas coincidencias de ideas, de tono y de vocabulario, demasiado frecuentes para ser fortuitas, podemos sugerir a título de hipótesis que se trata de reminiscencias. Sin duda Bolívar no tenía El Español en la mesa al redactar su Manifiesto; pero se admitirá por lo menos que se acordó de él para alimentar su reflexión.

Abramos aquí un paréntesis para señalar unos comentarios de El Español sobre Bolívar. En febrero de 1814, Blanco White dedica todo un artículo a "la campaña admirable" de Bolívar y rinde homenaje a su genio militar:

"La actividad y energía con que este pequeño ejército marchó y peleó hasta entrar en Caracas en agosto del mismo año, es seguramente extraordinaria”. ${ }^{22}$

Sin embargo las hazañas de Bolívar no le hacen perder a Blanco White su espíritu crítico. Con motivo de la muerte heroica del coronel Girardot, Bolívar había organizado "un viaje fúnebre-triunfal" para llevar su corazón de Valencia a Caracas. Ello excita los sarcasmos del periodista, que se burla de esta ridícula afición del Libertador a "las farsas republicanas" a la francesa. Basta este episodio para que Blanco White piense que Bolívar no es el genio superior, el hombre providencial que necesita América:

"...ese jefe que se hiciese respetar de aquellos pueblos, sentando con su conducta la base de ser un hombre moderado, incorruptible y defensor acérrimo de la justicia".

Sin embargo parece que Bolívar no le guardó rencor al periodista por sus acerbas censuras, ya que lo encomiaría más tarde en su Carta de Jamaica.

Bolívar escribe este texto (6 de septiembre de 1815) cuando el poder español está restaurado en Venezuela y Nueva Granada, "en un momento histórico en que la causa de la Independencia parece perdida irremisiblemente" ${ }^{23}$ Es un verdadero manifiesto de propaganda que publica con el fin de atraer la atención mundial y especialmente la de Inglaterra, en un momento crítico en que su apoyo es imprescindible. Con propósito clara-

21 "Observaciones sobre los debates de las Cortes", Esp. n. ${ }^{\circ}$ 14, 30 de mayo de 1811, T. III, pág. 140; "...la inexperiencia en materias prácticas de gobierno...”, "Carta al Americano”, Esp., T. V, pág. 420.

22 “América española, Caracas", Esp. n. ${ }^{\circ}$ 45, 28 de febrero de 1814, T. VIII, págs. 69 y ss.

23 CJ, págs. 55-75. Hernández Sánchez-Barba, M.: [Fragmento del Estudio preliminar al vol. I] Simón Bolívar. Discursos, Proclamas y Epistolario político, doc. 621 citado por Murillo Rubiera, F.: "Bolívar en la cultura y la política del siglo XX", en Filippi, ed.: Bolívar..., T. I, págs. 165-167. 
mente separatista analiza el estado de América a la luz del pasado y justifica la ruptura pintando la dominación española con los colores más oscuros de la "leyenda negra" y denunciando los errores de los nuevos gobiernos peninsulares. Sin embargo sabiendo que los ingleses no son nada amigos de repúblicas a la francesa, adopta un enfoque moderado propio para interesarlos, critica los excesos del sistema democrático y federal, e imagina la forma de los futuros estados americanos no sin referirse varias veces al constitucionalismo inglés.

Ha elegido unas fuentes que corresponden perfectamente a sus objetivos; se trata esencialmente de: Mier, Historia, 1813; Blanco White, El Español, 1810-1814; Walton, An Exposé of the Dissentions of Spanish América, 1814; D. de Pradt, Las Tres edades de las Colonias, París, 1802. Salvo la última, son obras recién publicadas en Londres que habían defendido la causa americana ante los ingleses. Vinculadas entre sí por tesis o documentos a menudo comunes, constituyen las fuentes primitivas de la historiografía de la Independencia. ${ }^{24}$ Precisemos que El Español es la primera cronológicamente y la más importante para la historia reciente, ya que las otras no hacen más que recoger sus tesis por lo que toca a la interpretación de los acontecimientos. Estas obras, subversivas por lo que se refiere al problema colonial, reflejan en lo que atañe al régimen político una ideología conservadora, hostil a la Revolución Francesa y cierta admiración por el modelo inglés. Bolívar explota libremente estas fuentes juiciosamente elegidas, adaptándolas a sus objetivos y según su genio y su experiencia política.

Antes de examinar la influencia de El Español, conviene precisar que aunque el autor suele señalar sus fuentes una vez, las utiliza mucho más de lo que deja suponer esta única mención. Es el caso, por ejemplo, cuando invoca un derecho feudal dimanado de los pactos del emperador Carlos $\mathrm{V}$ con los primeros conquistadores y cita a Guerra: "El emperador Carlos V formó un pacto...”. En realidad no sólo este párrafo sino también el anterior, que trata sobre la exclusión de los empleos y las prohibiciones económicas, no es más que un resumen, notable por su concisión, de varios pasajes de la Historia, Libro XIV, de Mier, quien había firmado su obra como José Guerra. ${ }^{25} \mathrm{Y}$ podrían multiplicarse los ejemplos para mostrar lo que

24 Pons: Blanco White..., 3. a parte, cap. III; "Influencia de la Historia en la historiografía de la Independencia“, en Mier: Historia, ed. crítica, Introducción, págs. CI-CX.

25 Sobre el pacto social, la magna carta, Mier: Historia, Lib. XIV, págs. 565-566, 571-614; las leyes prohibitivas, págs. 625-631; sobre los criollos excluidos de los empleos, págs. 624-625. 
debe a la Historia la Carta de Jamaica, por lo que se refiere no sólo a los hechos sino a las ideas. ${ }^{26}$

Volvamos a El Español. Después de mostrar que la independencia se justificaba por la larga serie de abusos de la época colonial, inspirándose en Mier, Bolívar llegaba a los acontecimientos recientes y remitía a su lector al periódico de Blanco:

"Sobre la naturaleza de los gobiernos españoles, sus decretos conminatorios y hostiles, y el curso entero de su desesperada conducta hay escritos, del mayor mérito, en el periódico "El Español" cuyo autor es el señor Blanco; y estando allí esta parte de nuestra historia muy bien tratada, me limito a indicarlo". ${ }^{27}$

Cabe advertir en seguida que Bolívar confiesa no sólo que había leído El Español sino que tenía de él un conocimiento profundo, general y detallado. Lo que llama en efecto la atención es que este elogio es incondicional; supone una adhesión sin ninguna reserva a todas las tesis fundamentales de Blanco White y a su interpretación de la historia reciente. Como si para probar la responsabilidad de los gobiernos peninsulares en el origen de la guerra y la subida del separatismo, Bolívar estimara que no hubiera podido decirlo mejor. Como si el periódico tuviera toda su confianza y fuera bastante famoso entre los americanos y los ingleses para que se ahorrara el trabajo de repetirlo. Todo eso no es extraño si se tiene en cuenta el apoyo que El Español había prestado a la causa americana, acción que había suscitado los encomios entusiastas de Roscio en la Gaceta de Caracas. Recordemos en efecto que Blanco White había defendido las primeras tesis de la Junta de Caracas; había puesto en duda la legitimidad de los gobiernos españoles para legislar sobre América; había demostrado la injusticia de la guerra declarada por la Regencia; había profetizado que la solución militar llevaría a la derrota ineluctable de España y a la ruptura moral definitiva con América. Todo ello permite entender que el Libertador suscriba enteramente la crítica de Blanco contra los gobiernos peninsulares y reconozca la importancia excepcional del periódico para justificar la lucha por la independencia.

Como Bolívar se adhería totalmente a las tesis fundamentales de $E l$ Español, no hay que extrañarse de que lo haya utilizado mucho más y sin mencionarlo, como lo ha hecho con la Historia de Mier. Primer ejemplo: recalca la imposibilidad para España de mantener su dominación en

26 Véase nota 1.

27 CJ, pág. 64. 
América y observa irónicamente el carácter aberrante de la política de reconquista militar:

" $i Q u e ́$ demencia la de nuestra enemiga pretender reconquistar la América, sin marina, sin tesoro y casi sin soldados! pues los que tiene, apenas son bastantes para retener a su propio pueblo en una violenta obediencia y defenderse de sus vecinos" ${ }^{28}$

Repárese inmediatamente en que las alusiones al mantenimiento del orden en España y a la defensa contra los franceses son completamente anacrónicas en 1815. Bolívar ha encontrado el argumento en El Español y lo utiliza sin atender a la cronología porque lo esencial para él es su incontrastable fuerza de propaganda. En efecto, no hace más que resumir una tesis fundamental de Blanco White a la que él mismo ha aludido anteriormente al hablar de la "desesperada conducta" de los gobiernos españoles: España, que carecía de medios financieros, navales y militares, no podía mantener su dominación en América y las tropas y los fondos sacrificados a la guerra colonial faltaban incluso para su propia defensa contra Napoléon. En estas circunstancias empeñarse en una solución militar era "un delirio... una locura". ${ }^{29}$ En cuanto a la imposibilidad para el gobierno de hacerse obedecer en España cuando pretendía gobernar en América, Blanco White había escrito con tono sarcástico, aludiendo a la resistencia del clero después de la abolición de la Inquisición:

“QQuién será tan necio que crea que los que apenas pueden valerse para gobernar a los clérigos y frailes de Cádiz, dirijan pueblos más allá del Océano? Semejante delirio no cabe en cerebro humano". ${ }^{30}$

Segundo ejemplo: Bolívar admite por un momento que España podía conseguir una pacificación temporal, pero afirma inmediatamente después que los americanos volverían a levantarse:"¿no volverán a formarse dentro de veinte años los mismos patrióticos designios...?" Otra vez se trata de un argumento de Blanco White: la pacificación era ilusoria pues la represión nutriría la rebelión. Excepto el plazo de veinte años, había emitido la misma hipótesis y había concluido de la misma manera:

28 CJ, pág. 59.

29 Esp. n. $^{\circ}$ 9, 30 de diciembre de 1810, T. II, p 251; n. ${ }^{\circ}$ 13, 30 de abril de 1811, T. III, pág. 34; n. ${ }^{\circ} 18,30$ de septiembre de 1811, III, pág. 463; n. ${ }^{\circ}$ 21, 30 de diciembre de 1811, T. IV, pág. 228: "Más que sistema, bueno o malo, parece furor o delirio"; y passim.

30 "Epílogo", Esp. n. ${ }^{\circ}$ 36, 30 de abril de 1813, T. VI, págs. 328-332. 
"De nada se servirá aquietar por el pronto a México y Buenos Aires... volverán con el menor motivo a tomar las armas en su defensa". ${ }^{31}$

Tercer ejemplo: Bolívar insiste en la imposibilidad para España de mantener el monopolio, porque no tenía medios para ello:

“...¿ipodrá esta nación hacer el comercio exclusivo de la mitad del mundo, sin manufacturas, sin producciones territoriales, sin artes, sin ciencias, sin política?"

Es una idea que El Español había lanzado el primero, en una fórmula notable por su concisión y su fuerza de convicción:

"Sin fondos, sin industria, sin máquinas ni saber, España es el país con menos derechos a exigir de sus colonias un comercio exclusivo". ${ }^{32}$

La habían repetido Mier en su Segunda Carta y Walton en su Exposé. Es patente que Bolívar se acuerda de la fórmula, como lo confirma el cotejo de los textos que permite seguir la filiación entre El Español y la Carta de Jamaica; las similitudes son flagrantes. ${ }^{33}$

Así pues resulta manifiesto que Bolívar, después de reconocer el valor incomparable de El Español para la defensa de los derechos de los americanos, ha recuperado su crítica de los gobiernos peninsulares para mostrar que la separación era irrevocable y justificar ante los ingleses la ruptura moral y psicológica con España.

Pero hay más. No se limitó Bolívar a utilizar en un sentido radical y subversivo la crítica al poder español de Blanco; se valió también en un sentido moderado y pragmático de una de sus tesis más originales: América no estaba madura para una verdadera independencia. El elogio de El Español está situado entre dos pasajes que desarrollan la idea, bastante inesperada en un jefe independentista, de que "la América no estaba preparada para desprenderse de la metrópoli, como súbitamente sucedió...”. Aquí Bolívar reconoce más o menos implícitamente que los americanos partidarios de la independencia eran en $1808-\mathrm{y}$ aun antes- extremadamente minoritarios. Anteriormente había indicado otra razón: América

31 CJ, pág. 59; Esp. n. ${ }^{\circ}$ 47, 30 de junio de 1814, T. VIII, pág. 306.

32 CJ, pág. 59; Esp. n. ${ }^{\circ}$ 4, 30 de julio de 1810, T. I, pág. 27.

33 Mier cita libremente dos veces el periódico: "Usted mismo ha dicho en otra parte que España, sin talentos, industria ni saber, era la menos digna de exigir una sumisión entera de los americanos”. SC, pág. 209; “...porque España, sin industria, sin saber, sin manufacturas, ni marina (y sin Provincias ahora) no puede llevar nada a América”, ibídem, pág. 293. Walton traduce pura y simplemente la frase sacada de El Español sin mencionar la fuente (An Exposé of the dissentions of Spanish America, Londres, 1814, pág. 308). 
tenía una identidad incierta: "no somos indios ni europeos, sino una especie media...". Pero la razón principal es que los americanos del sur, al contrario de los norteamericanos, carecían de experiencia política en su administración interior para asumir las responsabilidades de un estado independiente porque España los había mantenido en la "servidumbre". En resumidas cuentas, Bolívar, teniendo en cuenta la opinion general de los pueblos, la diversidad de la población, la herencia del pasado colonial y la diferencia de evolución entre la América del Sur y los Estados Unidos, admitía que ésta no estaba preparada para asumir la independencia, que el sistema democrático no le convenía de momento y era necesaria una etapa de transición antes de "elevarse al goce de la libertad". ${ }^{34}$

Este análisis, notable por su moderación y su realismo, confiere a la doctrina de Bolívar una profunda originalidad en el pensamiento político de la emancipación. La idea de que la independencia era prematura era moderna y aun modernísima, ya que la confirmó en general toda la historia posterior de Hispanoamérica. Iba a contracorriente de todo lo que se pensaba en la época. Bien sabido es que en los años anteriores y posteriores a 1810, el ejemplo de los Estados Unidos constituyó para los hispanoamericanos una incitación a sacudir el yugo y después a imitar su régimen republicano. Que la América española estaba perfectamente madura para proclamar su independencia siguiendo el ejemplo de los Estados Unidos, era la tesis optimista que mantenían todos los líderes independentistas, Miranda o Mier por ejemplo. ${ }^{35}$

Por el contrario, Blanco White fue el primer escritor que rechazó esta idea y aunque favorable a la independencia en principio, afirmó que era prematura en 1811. Se fundaba en un análisis que revelaba un profundo conocimiento de la situación política, económica y social de la América española a principios del siglo XIX, que se apoyaba en Humboldt, fuente que cita también Bolívar. La primera razón que aducía era que la opinión general no estaba decidida por la independencia; sólo una minoría de criollos pensaba en ella. La segunda razón era que América todavía carecía de cohesión social y estaba buscando su identidad: su población heterogénea, dividida en razas y castas con intereses opuestos, no formaba "un verdadero pueblo". ${ }^{36} \mathrm{La}$ tercera razón que invocaba Blanco White contra la inde-

$34 C J$, págs. 62-67.

35 Mier, PC, pág. 10; Miranda, F. de: Edinburgh Review, 1809, vol. XIII, págs. 277-311; vol. XIX, págs. 333-353.

36 “Contestación... a la Carta de un Americano", Esp. n. 24, T. IV, págs. 424-425. 
pendencia inmediata era que, a diferencia de las colonias inglesas, los americanos españoles no habían podido hacer el aprendizaje de la libertad, o sea adquirir una experiencia política - "no han tenido jamás parte en su administración interior" - porque el despotismo los había mantenido en la pasividad: "en la completa esclavitud que pinta Mr Burke". ${ }^{37}$ "No vuelvan los ojos a los Estados Unidos - repetía Blanco White a los americanos-; la América española no ha pasado aún el noviciado de la libertad...”. Por eso les había aconsejado que se limitasen a pedir una "independencia moderada" que fuera una etapa de transición en la que hubieran podido aprender a manejar "su administración interior" y hacer reformas imprescindibles en el dominio económico, social y educativo, antes de alcanzar la verdadera independencia. ${ }^{38}$

No cabe duda de que, al hacer hincapié en el concepto de la falta de madurez de América, debida a una identidad incierta y a la inexperiencia política, al rechazar el ejemplo norteamericano por estar completamente inadaptado a la realidad político-social de los estados nacientes y al reconocer la necesidad de una etapa de transición entre el régimen colonial y la verdadera libertad, Bolívar ha adoptado el análisis lúcido y realista de Blanco White para confirmar sus propias intuiciones; los dos coinciden en una idea esencial: para asumir la realidad del poder los americanos debían tener en cuenta el poder de la realidad.

Exactamente lo mismo acontece cuando Bolívar reconoce cuán difícil era para una colonia recién liberada del despotismo convertirse de repente en una república. Preguntándose sobre la capacidad de sus compatriotas para asumir los riesgos de la libertad y mantener una república, Bolívar escribe:

“...¿seremos capaces de mantener en un verdadero equilibrio la difícil carga de una república? ¿Se puede concebir que un pueblo recientemente desencadenado se lance a la esfera de la libertad, sin que, como a Icaro, se les deshagan las alas y recaiga al abismo? Tal prodigio es inconcebible".

No parece sino que Bolívar tiene en la mente un pasaje donde Blanco White había recalcado esta imposibilidad, había condenado el paso precipitado de una colonia oprimida a la república y había evocado el peligro de caer en "el golfo borrascoso de la democracia":

37 Esp. n. ${ }^{\circ} 22,30$ de enero de 1812, T. IV, págs. 241-278; "América", Esp. n. ${ }^{\circ} 10,30$ de enero de 1811, T. II, págs. 334-339.

38 “Contestación... a la Carta de un Americano", Esp. n. ${ }^{\circ}$ 24, T. IV, págs. 424-425. 
“ ¿Tan pronto se convierte una colonia esclavizada en una república? ¿Por qué había de ser más ignominioso para el gobierno de Caracas enseñar poco a poco a ser libre que no arrojarlo de repente en medio del golfo borrascoso de la democracia?".

Amén de la similitud de la idea y del giro — interrogativo — se notará sobre todo la sorprendente analogía de la metáfora final: la caída en el mar — "el abismo, el golfo". 39

En realidad Bolívar, hombre de acción y de orden, experimenta cierta desconfianza por la democracia, régimen débil que puede llevar a la anarquía. Al lamentar la inexperiencia política de los americanos, adopta un punto de vista que dista mucho de ser democrático y llama la atención por su aspecto conservador:

"Si hubiésemos siquiera manejado nuestros negocios... gozaríamos también de la consideración personal que impone a los ojos del pueblo cierto respeto maquinal que es tan necesario conservar en las revoluciones".

De nuevo suscribe a una advertencia antidemocrática de Blanco White que en su "Contestación a la Carta de un Americano" había precavido a los americanos contra "esta cadena de revoluciones" y había subrayado la necesidad para los gobernantes de conservar "el respeto reverencial" del pueblo:

“...la poderosa ilusión del respeto reverencial y de costumbre, que sólo se concilian los individuos o los cuerpos después de muchos años de establecidos en el mando....". 40

Observamos aquí otra similitud casi literal; Bolívar, una vez más, abrevia la expresión de Blanco White: "respeto reverencial y de costumbre" se convierte en "respeto maquinal".

No sólo Bolívar se acordó de El Español para criticar la democracia porque estaba inadaptada a una antigua colonia recién salida de la tutela española, sino que se adhirió al constitucionalismo inglés que Blanco White, con espíritu moderado, había aconsejado para España. Importa señalar que optaba por "un medio entre extremos opuestos", o sea los de la democracia pura — "las anarquías demagógicas"- y los de la tiranía autocrática. Es exactamente este "camino medio... un justo medio", o sea un régimen moderado de tipo inglés, el que había elegido Blanco White

$39 C J$, pág. 67; Esp. n. ${ }^{\circ} 19,30$ de octubre de 1811, T. IV, pág. 44.

$40 C J$, pág. 63; "Contestación... a la Carta de un Americano”, Esp. T. IV, pág. 422. 
para España y por la misma razón: evitar el absolutismo tradicional y la democracia a la francesa que llevaba a la anarquía y luego a la tiranía. ${ }^{41}$

Conviene advertir que el concepto de que la América española no estaba preparada para la independencia absoluta y la democracia era un punto importante de la polémica entre Blanco White y Mier. No parece sino que Bolívar, después de leer atentamente esta polémica, ha rechazado las tesis del mexicano caracterizadas por cierto optimismo nacionalista y ha adoptado el análisis de Blanco White marcado por el realismo. Todo eso parece comprobado por el hecho de que Bolívar conocía la Segunda Carta al Español. El famoso pasaje sobre un Congreso en Panamá que hace de Bolívar el precursor del panamericanismo - "Es una idea grandiosa formar de todo el Mundo Nuevo una sola nación..."- se inspira en Mier, Segunda Carta. ${ }^{42}$

Se podría pensar que, con el tiempo, Bolívar hubiera olvidado El Español. Nada de eso. En el Discurso de Angostura (1819) procuró superar la anarquía democrática y federal tomando como modelo el régimen constitucional inglés. Para convencer a los diputados apegados a la Constitución de 1811, resumió o desarrolló todas las ideas que, acordándose del análisis realista y moderado de Blanco White, había expresado ya en el Manifiesto de Cartagena o la Carta de Jamaica: falta de madurez de América debida a una identidad incierta, a una "sociedad heterogénea" y al pasado colonial que no había permitido a los americanos conocer "la ciencia del gobierno"; importancia de "la consideración personal" debida por el pueblo a los gobernantes en las revoluciones; imposibilidad para Venezuela de seguir el ejemplo, "demasiado lisonjero", de los Estados Unidos; imposibilidad de asimilar la situación de "dos estados tan distintos como el Inglés Americano y el Americano Español"; dificultades para aplicar el sistema representativo y federal en una colonia recién salida de la tutela española. Por último, de la misma manera que Blanco White había previsto que era necesario "un siglo de paz y leyes" para liquidar la herencia del pasado

41 CJ, pág. 69; Esp. n. ${ }^{\circ} 38,30$ de junio de 1813, T. VI, págs. 415-416; "Conclusión de esta obra", Esp. n. ${ }^{\circ} 47,30$ de junio de 1814, T. VIII, pág. 295.

$42 C J$, pág. 72; Esp. n. ${ }^{\circ} 24,30$ de abril de 1812, T. IV, págs. 424-425; "Un Congreso, pues, junto al istmo de Panamá, árbitro único de la paz y la guerra en todo el Continente Colombiano, no sólo contendría la ambición del Principino del Brasil y las pretensiones que pudiesen formar los Estados Unidos sino a la Europa toda... Las desgracias del mundo viejo debieran dar estas lecciones al nuevo, donde sólo son practicables por la homogeneidad de la lengua, educación, costumbres, religión y leyes" SC, págs.197-198. Murillo Rubiera, F.: "La solidaridad americana en el pensamiento internacionalista de Andrés Bello", Quinto Centenario, Madrid, 1986, págs. 19-61. 
colonial, así Bolívar reconoce la necesidad de una larga etapa de reformas - "largo tiempo"- antes de liquidar las reliquias de la dominación española. ${ }^{43}$

Sin embargo lo que distingue el Discurso de Angostura de los escritos anteriores es que Bolívar se entrega a una crítica del democratismo jacobino, fundado en principios tomados de la Revolución Francesa, los Estados Unidos y la España liberal que habían marcado la Constitución de 1811; por otra parte, trata de imaginar un orden constitucional que pudiera superar las deficiencias de la Primera República. En esta crítica y en este proyecto es donde la influencia de Blanco White llama más la atención.

Cuando Bolívar rechaza la democracia absoluta, "las brillantes formas de libertad... el ejemplo... demasiado lisonjero... la libertad absoluta... las teorías abstractas...que producen la perniciosa idea de una libertad ilimitada", porque llevan a la anarquía o al poder absoluto, no parece sino que se oye a Blanco White. Este, después de convertirse al conservadurismo británico de Burke, había atacado a los liberales españoles y a los republicanos de Caracas por haber instalado un régimen democrático fundado en principios abstractos, brillantes, pero peligrosos en práctica, copiados de la Revolución Francesa. No había dejado de denunciar "la libertad absoluta... la igualdad en abstracto... los planes de libertad que aparecen tan sencillos y brillantes... los prospectos lisonjeros, las teorías abstractas...". Y había profetizado que ese régimen frágil llevaría a la anarquía y luego a un nuevo despotismo. ${ }^{44}$ Dichas ideas, decía él pensando en Francia, no eran más que "una multitud de cálculos abstractos que lejos de ser fruto de la experiencia, eran planes absurdos de personas que estrellaron a su patria en el escollo de la anarquía". Aunque no se puede excluir una coincidencia por ser la imagen un tópico, parece que Bolívar se acuerda de este pasaje cuando escribe:

"La libertad indefinida, la democracia absoluta son los escollos a donde han ido a estrellarse todas las esperanzas republicanas". ${ }^{45}$

43 "Contestación... a la Carta de un Americano", Esp. n. ${ }^{\circ} 24,30$ de abril de 1812, T. IV, pág. 420; CJ, pág. 111.

44 "Constitución para la Nación española" de A. Flórez Estrada, Esp. n. ${ }^{\circ}$ 8, 30 de noviembre de 1810 , T. II, págs. $135-136,140 ;$ n. $^{\circ} 17,30$ de agosto de 1811 , T. III, pág. $412 ;$ n. $^{\circ} 30,30$ de octubre $^{\circ}$ de 1812, T. V, pág. 420; n. ${ }^{\circ} 31,30$ de noviembre de 1812, T. V, págs. 473-486; n. ${ }^{\circ} 33$, 30 de enero de 1813, T. VI, pág. 15.

45 Esp. n. ${ }^{\circ} 36,30$ de abril de 1813, T. VI, pág. 274; DA, pág. 119. 
Después de condenar el régimen democrático por su debilidad y su tendencia a la anarquía, Bolívar hace hincapié en la necesidad de crear un régimen que sea en primer lugar fuerte y eficiente, pero en segundo lugar moderado, es decir que pueda conciliar la autoridad con la libertad. Es exactamente este tipo de gobierno el que había propuesto Blanco White. ${ }^{46}$ Para imaginar este régimen, Bolívar, acudiendo a las lecciones de la experiencia y de la historia y rechazando "las brillantes formas de libertad", elige como modelo la Constitución inglesa. Al recomendar a los legisladores el estudio de ésta "por ser la más digna de servir de modelo", al precisar que deben imitarla pero sin imitación servil, porque el sistema de gobierno debe "ser apropiado a la naturaleza y al carácter de la nación", parece que se hace eco de verdaderas obsesiones de Blanco White. Este no había dejado de hacer el elogio de la Constitución inglesa cuya estabilidad, que oponía a "los planes de libertad brillantes" a la francesa, había sido sancionada por la experiencia de los siglos; y había recomendado a las Cortes que la tomasen como modelo pero sin copiarla servilmente porque "los principios fundamentales deben ser comunes a todas las naciones y el modo de ponerlos en práctica debe ser peculiar de cada una". ${ }^{47}$

La República que imagina Bolívar, con un presidente vitalicio en vez de un rey, se parece mucho a la monarquía limitada a la inglesa que había recomendado Blanco White para España. Propone un gobierno fuerte y centralizado en su estructura pero liberal en sus principios: soberanía del pueblo, división y equilibrio de los poderes, libertad civil, de conciencia, de imprenta. Blanco White había propuesto la misma forma de gobierno, con ejecutivo fuerte, fundado en los mismos principios, excepto la soberanía del pueblo, pues quería mantener la soberanía real con todas sus prerrogativas.

Sin embargo es en el proyecto del Senado hereditario donde la influencia de El Español aparece más notable. Como en la Carta de Jamaica, Bolívar considera la creación del Senado como el mejor medio para fundar un régimen moderado y estable. Sería un elemento de equilibrio entre los poderes del gobierno y de la Cámara de Representantes: "adicto al gobierno por el interés de su propia conservación pararía los rayos del gobierno y rechazaría las olas populares...servirá de contrapeso para el gobierno y para el pueblo". Ahora bien, otra idea fija de Blanco White era asentar la estabili-

46 DA, págs. 118-119; Esp. n. ${ }^{\circ} 32,30$ de diciembre de 1812, T.V, pág. 559; n. ${ }^{\circ} 25,30$ de mayo de 1812, T. V, pág. 12.

47 DA, págs. 113-114; Esp. n. ${ }^{\circ} 8,30$ de noviembre de 1810, T. I, pág. 148 nota. 
dad del régimen constitucional mediante la creación de una segunda cámara cuyos intereses se vincularan con los del gobierno y que pudiera resistir a las inclinaciones populares de las Cortes y al autoritarismo del gobierno. Esta idea de equilibrio, repetida a menudo, se expresa dos veces con una imagen de la que al parecer se acordó Bolívar: "servirá de contrapeso". ${ }^{4}$

$\mathrm{Si}$ ahora entramos en el detalle, las huellas de El Español aparecen flagrantes en un pasaje sobre el Senado, donde Bolívar se inspira muy ceñidamente en un párrafo de un número que no podía dejar de llamar su atención siquiera porque este número, que ya hemos señalado, contiene comentarios sobre "la campaña admirable" y su propia persona. El motivo de la creación de la segunda cámara y el sistema de nombramiento son los mismos. ${ }^{49}$ Para evitar que el porvenir de la República dependiera de un cambio de mayoría en la Cámara de Representantes —el juego aventurado de las elecciones sometido al pueblo ignorante- el Libertador imaginaba crear un Senado hereditario que pudiera garantizar la continuidad del régimen: "Todo no se debe dejar al acaso y a la ventura de las elecciones".

Ahora bien, después de la victoria de los conservadores en las elecciones para las Cortes ordinarias (1813-1814) con el mismo propósito - asegurar la estabilidad del régimen constitucional, evitar que su existencia se viera expuesta a un cambio de mayoría en las Cortes-Blanco White había recomendado de nuevo la creación de una segunda cámara.Y en una forma que presenta cierta similitud: "La existencia de la Constitución misma depende de que no se deje todo a una votación". Más arriba asoma la idea de casualidad: "el vuelco de un dado".

Por lo que se refiere a los requisitos de nombramiento, Bolívar proponía que los senadores fuesen elegidos la primera vez por el Congreso entre los libertadores de Venezuela, como prueba de gratitud por su papel en la fundación de la República - "sus primeros bienhechores". En cuanto a Blanco White, había aconsejado que los miembros de la segunda cámara fuesen elegidos entre los individuos de la Comisión constitucional, en premio de su celo por la libertad de la patria - "beneméritos de ella". Bolívar añadía que los sucesores, hereditarios, serían educados "en un Colegio especialmente destinado para instruirlos". Salvo esta precisión -el Colegio - Blanco White había sugerido que "convendría perpetuar este privilegio en sus herederos a quienes podrían educar" en el amor a la libertad pág. 239.

48 DA, págs. 114-116. Esp. n. ${ }^{\circ}$ 42, 30 de octubre de 1813, T. VII, pág. 240; imagen repetida,

49 DA, pág. 115; Esp. n. ${ }^{\circ} 45,28$ de febrero de 1814, T. VIII, pág. 94. 
y a la Constitución. De este modo Bolívar esperaba "conservar hasta la última posteridad una raza de hombres virtuosos, prudentes y esforzados", fundadores de la República, mientras que Blanco White había imaginado que "así se perpetuaría una raza de defensores de las leyes fundamentales de la monarquía". Por cierto que Bolívar, quien no quiere violar el principio de igualdad, cuida mucho de no hablar de privilegio; pero consta que su propósito es tan conservador como el de Blanco White: se trata de crear una nueva aristocracia cuyos méritos derivan de los padres fundadores de la República, como lo confirma más tarde el proyecto de distribución de los bienes nacionales a los oficiales del ejército. Por si acaso todo ello no bastara, señalemos que al recomendar el estudio de las instituciones inglesas a los legisladores, el Libertador reproduce casi literalmente un pasaje de El Español, sacado es verdad de otro número. Escribe:

“... os recomiendo... el estudio de la Constitución Británica que es la que parece des-
tinada a operar el mayor bien posible a los pueblos que la adopten, pero por perfecto
que sea estoy muy lejos de proponeros su imitación servil”.

Y Blanco White:

"Cuando recomiendo las leyes y costumbres inglesas, fruto del saber y experiencia de los siglos, no es mi ánimo proponerlas como un dechado que se debe copiar servilmente". ${ }^{50}$

La filiación entre El Español y Bolívar nos parece corroborada indirectamente por el periodista que reconoció en el Discurso de Angostura la realización de su propio ideario político. En 1823, en las Variedades, n. $^{\circ} \cdot 1$, después de publicar una noticia biográfica de Bolívar, aprobó el discurso con el entusiasmo de quien veía por fin seguidos, por uno de los más famosos americanos, los consejos que había dado en materia constitucional. Hizo un curioso resumen del texto donde, más que las ideas de Bolívar, expresaba sus propias obsesiones. Lo centraba en la Constitución inglesa "que ha sido el resultado de la experiencia y no de sueños lisonjeros y brillantes" pero que había que adaptar a las "circunstancias" del pueblo. Al mencionar los principios republicanos, aunque omitía la soberanía del pueblo, hacía hincapié en los que él mismo no había dejado de recomendar, añadiendo comentarios personales que expresaban su aprobación entusiasta y que subrayamos:

50 DA, pág. $114 ;$ Esp. n. ${ }^{\circ} 8,30$ de noviembre de 1810, T. II, pág. 148 nota. 
“... la división de poderes, único medio de evitar toda especie de tiranía; la libertad de conciencia, único medio de criar ánimos francos y denodados; la libertad de la imprenta, antídoto sin igual de los abusos públicos...". ${ }^{51}$

No es exagerado concluir que de la misma manera que Bolívar en 1815 había suscrito enteramente las tesis subversivas de El Español, así Blanco White expresaba implícitamente su total conformidad con el Discurso de Angostura en materia constitucional. Dos años después confirmaba su estima y admiración al Libertador. Al saludar la victoria de Ayacucho, rindió homenaje a Bolívar encomiando su integridad moral, particularmente su desinterés:

"Del Libertador Bolívar siempre he tenido opinión muy favorable, no tanto por sus extraordinarios talentos militares, como por el noble desinterés que constituye su carácter". ${ }^{52}$

La influencia de Blanco White en Bolívar que acabamos de poner en evidencia permite tratar de comprender por qué un historiador como Stoetzer ha encontrado resonancias burkeanas en el ideario político del Libertador, aunque no existen pruebas de que fuera influenciado por Edmund Burke, que había fallecido en $1797 .{ }^{33}$ En sus Reflexiones sobre la Revolución francesa, éste había expuesto una filosofía conservadora e incluso contrarrevolucionaria que resumimos a grandes rasgos. Burke rechazaba los principios abstractos en el tratamiento de las cuestiones prácticas y la teoría de los derechos del hombre. Acudía a la historia y la experiencia para guiarse en los problemas políticos y hacía el elogio del constitucionalismo inglés que había fundado un gobierno estable y equilibrado. Finalmente recomendaba tener en cuenta las consideraciones de conveniencia, de circunstancias - palabra-clave de su vocabulario y regla fundamental para él de la acción política. Aunque, como ya lo hemos visto, estos elementos se hallan en el pensamiento de Bolívar, la dificultad es que no se ha podido probar la influencia directa de Burke en Bolívar. Para resolverla nos atrevemos a sugerir una hipótesis: como otros hispanoamericanos, el Libertador tuvo conocimiento indirecto de las ideas burkeanas gracias a El Español que las había recogido, actualizado y difundido en una lengua más asequible para ellos.

51 Variedades o Mensagero en Londres, Londres, R. Ackermann, 1823-1825, 1 de enero de 1823 , n. ${ }^{\circ} 1$, vol. I, pág. 12 col. a.

52 Var., 1 de abril de 1825 , n. $^{\circ} 7$, págs. 199-200. 
Al llamar la atención sobre El Español como una de las fuentes importantes del Manifiesto de Cartagena, de la Carta de Jamaica y del Discurso de Angostura, no hemos querido poner en duda la originalidad de Bolívar: aunque se adhería a las críticas de Blanco White contra los republicanos de 1811, sacaba una conclusión diametralmente opuesta: había que seguir la lucha; por otra parte adaptaba el constitucionalismo británico vulgarizado por Blanco White a las exigencias de los nuevos estados. De las coincidencias que hemos señalado sin pretender la exhaustividad, ${ }^{54}$ podemos por lo menos inferir la existencia indudable de un vínculo ideológico, de una comunidad de ideas entre el publicista y el Libertador. Consciente del valor histórico y crítico de El Español, Bolívar se inspiró en él para fomentar su reflexión; lo utilizó en un sentido subversivo y conservador como lo hicieron también otros líderes hispanoamericanos; en primer lugar para poner la historia al servicio de la lucha contra España, en segundo lugar para analizar las dificultades de la independencia o de la democracia en las antiguas colonias y por último para imaginar el tipo de gobierno que conviniera a los nacientes estados.

Para concluir queda por tratar de explicar por qué Bolívar se acordó tan a menudo de Blanco White y se adhirió a sus ideas: no parece sino que El Español desempeñó un papel de catalizador, precisando y reforzando sus propias opiniones y permitiéndole elaborar entonces nuevas soluciones. Como advierte Manuel Fraga Iribarne:

"Este educador de los pueblos, como Napoleón, desconfía de los "ideólogos", de los "buenos visionarios", de los "espíritus partidarios". Bolívar es un hombre culto de estilo anglosajón, no un ateneista de corte latino. Realismo y moderación, nada de radicalismo y utopía". ${ }^{55}$

53 Stoetzer, O.: El pensamiento político en la América española durante el período de la emancipación, 1789-1825, Madrid, 1966, vol. II, págs. 151-164. Edmund, Burke: Réflexions sur la Révolution de France, 1790, Paris-Genève [reprint], 1980.

54 Se observan otras huellas de El Español en Bolívar: sobre la necesidad de la unión de los americanos, $M C$, pág. 13, $C J$, pág. 74, y Esp. n. ${ }^{\circ} \cdot 9,30$ de diciembre de 1810, T. II, pág. 251, n. ${ }^{\circ} 24,30$ de abril de 1812, T. IV, pág. 425; sobre una guerra larga terminada por la victoria de los americanos, $C J$, pág. 72 ; Esp. n. ${ }^{\circ} 43,30$ de noviembre de 1813 , T. VII, pág. 320 y passim; sobre la voluntad general que no es infalible, el pueblo "desconoce sus verdaderos intereses... se engaña”, DA, págs. 114-115 y Esp. n. ${ }^{\circ}$ 24, T. IV, págs. 411-412; Burke: Réflexions..., págs. 103, 417; sobre el principio de igualdad, DA, págs. 110-111; Esp. n. ${ }^{\circ} 33,30$ de enero de 1813, T. VI, págs. 17-18; n. ${ }^{\circ} 8,30$ de noviembre de 1810, T. II, págs. 140-141; Burke: Réflexions..., págs. 70-71, 96, 119-122; sobre la necesidad de oponerse al "despotismo deliberante" de la asamblea única que provoca la anarquía, la oligarquía y la autocracia, $D A$, pág. 123; Esp. n. ${ }^{\circ} 33$, T. VI, pág. 15; Burke: Réflexions..., págs. 263, 411, 421; sobre los "gobiernos paternales", CJ, pág. 68; Esp. n. ${ }^{\circ} 24$, T. IV, pág. 420; n. ${ }^{\circ} 36$, T. VI pág. 329; sobre la educación popular, el sistema de Bell y Lancaster, DA, pág. 121; Esp. n. ${ }^{\circ} 45$, VIII, págs. 2-23; n. ${ }^{\circ} 24$, T. IV, págs. 424-425.

55 Fraga Iribarne, M.: "El pensamiento político de Bolívar", doc. 620, citado por Murillo Rubiera, F.: "Bolívar en la cultura” en Filippi, ed.: Bolívar..., T. I, págs. 163-165. 
Realismo y moderación, pragmatismo inglés — aunque no falta el idealismo- tales son precisamente los rasgos que pueden caracterizar el ideario político de Blanco White. En definitiva si El Español ejerció sobre el pensamiento de Bolívar una atracción indudable quizás sea porque encontró en él el reflejo de ciertas de sus propias tendencias y algo que admiraba en secreto: el pragmatismo iluminado por una mente clara. 